\title{
Alimentação de suínos em terminação com dietas contendo ractopamina e extratos cítricos: desempenho e características de carcaça
}

\author{
Pigs fed containing ractopamine and citrus extracts: performance and carcass characteristics
}

\author{
Carlos Augusto Rigon Rossi Paulo Alberto LovattoII Gerson Guarez Garcia ${ }^{\text {II }}$ \\ Cheila Roberta Lenhen ${ }^{\text {III }}$ Glauber Valentim Porolnik ${ }^{\text {III }}$ Marcos Speroni Ceron $^{\text {IV }}$ \\ Gustavo Dias Lovato ${ }^{\mathrm{IV}}$
}

\section{RESUMO}

\begin{abstract}
Um experimento avaliou a adição de ractopamina e extratos citricos a dietas de suínos em terminação. Foram utilizados 108 suinos (54 machos e 54 fêmeas) em um delineamento de blocos completos ao acaso, sendo o sexo o fator de bloqueamento e nove os tratamentos: T1. controle (C) (Oppm de ractopamina e 0ppm de extratos citricos), T2. C+10RAC (ractopamina, em ppm), T3. C+20RAC, T4. C+250EC (extratos citricos, em ppm), T5. C+500EC, T6. C+250EC+10RAC, T7. $C+250 E C+20 R A C, \quad T 8 . \quad C+500 E C+10 R A C$ e T9. $C+500 E C+20 R A C$. O peso vivo final $(109,9 \pm 3,6 \mathrm{~kg})$, consumo de ração $\left(2,6 \pm 0,2 \mathrm{kgd}^{-1}\right)$, ganho de peso $\left(1,0 \pm 0,1 \mathrm{kgd}^{-1}\right)$, conversão alimentar $(2,7 \pm 0,2)$, comprimento de carcaça $(97,0 \pm 2,7 \mathrm{~cm})$, profundidade de músculo $(56,1 \pm 5,6 \mathrm{~mm})$ e $\mathrm{pH}(5,9 \pm 0,3)$ não foram influenciados pelos tratamentos. Sobre o peso de carcaça, o efeito foi somente do tratamento com 20ppm de ractopamina em relação a $10 \mathrm{ppm}$ de ractopamina, sendo 5,7\% superior. $A$ espessura de toucinho do grupo controle foi $35 \%$ superior aos níveis de ractopamina, e a interação foi 500ppm de extratos citricos e 10ppm de ractopamina. A carne magra do controle foi $5,3 \%$ inferior em relação aos niveis de ractopamina. $A$ alimentação de suinos em terminação com dietas contendo ractopamina, extratos citricos e suas interações não altera o desempenho, mas influencia algumas características de carcaça.
\end{abstract}

Palavras-chave: ácido ascórbico, agonista $\beta$-adrenérgico, bioflavonóides, nutrição.

\section{ABSTRACT}

This study was carried out to evaluate the effect of the addition of the citrus extracts and ractopamine in finishing pig diets. A Hundred eight pigs were used (54 males and 54 females) in a completely randomized design, blocked by sex and distributed in nine treatments: T1. control (C) (Oppm of the ractopamine e 0ppm of the citrus extracts), T2. C+10RAC (ractopamine, ppm), T3. C+20RAC, T4. C+250EC (citrus extracts, ppm), T5. C+500EC, T6. C+250EC+10RAC, T7. $C+250 E C+20 R A C, \quad T 8 . \quad C+500 E C+10 R A C$ and T9. $C+500 E C+20 R A C$. The final body weight $(109.9 \pm 3.60 \mathrm{~kg})$, feed intake $\left(2.6 \pm 0.24 \mathrm{~kg} \mathrm{~d}^{-1}\right)$, body weight gain $\left(1.01 \pm 0.09 \mathrm{~kg} \mathrm{~d}^{-1}\right)$, feed conversion ratio $(2.7 \pm 0.25)$, carcass length $(97 \pm 2.71 \mathrm{~cm})$, depth muscle $(56.1 \pm 5.63 \mathrm{~mm})$, and $\mathrm{pH}(5.9 \pm 0.33)$ were not affected by treatments. There was a significant effect for the treatment with 20ppm of ractopamine, which was 5.7 higher, in relation to the treatment with $10 p p m$ of ractopamine. The backfat thickness of control group was 35\% higher than the ractopamine levels and the interaction was of $10 \mathrm{ppm}$ of ractopamine and 500ppm of citrus extracts. The lean meat in the control group was on average, $5.3 \%$ lower in relation to the ractopamine levels. Feeding of finishing pigs with diets containing ractopamine, citrus extracts and their interactions didn't affect performance, however affected some carcass characteristics.

Key words: ascorbic acid, bioflavonoids, $\beta$-adrenergic agonist, nutrition.

\section{INTRODUÇÃO}

Aumentar a quantidade de carne na carcaça de suínos tem sido o objetivo da indústria e do suinocultor, pois melhora a rentabilidade e diminui os

'Programa de pós-graduação em Zootecnia, Universidade Federal de Santa Maria (UFSM), Av. Roraima, 1000, Cidade Universitária, Bairro Camobi, 97105-900, Santa Maria, RS, Brasil. E-mail: carlos.rossi.mv@gmail.com. Autor para correspondência.

"Departamento de Zootecnia, UFSM, Santa Maria, RS, Brasil.

IIIPrograma de pós-graduação em Zootecnia, UFSM, Santa Maria, RS, Brasil.

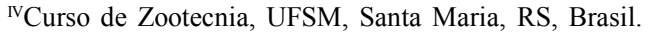


custos de produção. Na fase de terminação, a composição da carcaça muda, principalmente $o$ aumento da deposição lipídica, o que reduz a eficiência alimentar. Isso exige adequação da nutrição e do manejo alimentar. Para tanto, diversas alternativas nutricionais ou de regulação metabólica têm sido avaliadas. Uma delas é o uso da ractopamina, que atua sobre a partição de nutrientes, melhorando o desempenho e as características de carcaça de suínos em terminação (MOODY et al., 2000). Essa melhora se dá pela maior taxa de deposição proteica (SCHINCKEL et al., 2003). Outra alternativa é o uso de extratos vegetais na dieta, com destaque para os cítricos (MASON et al., 2005).

Os principais componentes dos extratos cítricos são os compostos fenólicos (bioflavonoides ou flavonoides) e o ácido ascórbico. Os bioflavonoides são antioxidantes naturais, com ações antiinflamatórias, antimicrobianas, antialergênicas e imunoestimulantes (CUSHNIE \& LAMB, 2005). O ácido ascórbico participa de diversos processos metabólicos, como a formação do colágeno e síntese de epinefrina, corticoesteroides e ácidos biliares (PION et al., 2004). Além de cofator enzimático, o ácido ascórbico participa dos processos de óxido-redução, aumentando a absorção de ferro e a inativação de radicais livres (PADAYATTY et al., 2003). Os benefícios da utilização terapêutica do ácido ascórbico em suínos são observados no desempenho, estresse pré-abate e na qualidade da carne (PION et al., 2004).

Pelas propriedades individuais e ação sinérgica de seus princípios ativos, o uso de extratos cítricos nas dietas pode melhorar o desempenho dos suínos na terminação e as características de carcaça. Embora existam informações positivas relacionadas ao sinergismo dos constituintes dos extratos cítricos, ainda não há relatos do uso associado com a ractopamina. Este trabalho foi conduzido, portanto, com o objetivo de estudar o desempenho e as características de carcaça de suínos alimentados com dietas contendo ractopamina, extratos cítricos e suas interações.

\section{MATERIAL E MÉTODOS}

O trabalho foi realizado de julho a agosto de 2008, totalizando 52 dias de experimento. Foram utilizados 108 suínos (54 machos castrados e 54 fềmeas) meio-irmãos paternos, oriundos de criação comercial, com peso vivo médio inicial de $61 \mathrm{~kg}$. O delineamento experimental foi de blocos completos ao acaso, sendo o sexo utilizado como fator de bloqueamento. Foram utilizados nove tratamentos na seguinte ordem: controle (C) (0ppm de ractopamina e 0ppm de extratos cítricos), $\mathrm{C}+10 \mathrm{RAC}$ (ractopamina, em ppm), C+20RAC, C+250EC (extratos cítricos, emppm), $\mathrm{C}+500 \mathrm{EC}, \mathrm{C}+250 \mathrm{EC}+10 \mathrm{RAC}$, $\mathrm{C}+250 \mathrm{EC}+20 \mathrm{RAC}, \mathrm{C}+500 \mathrm{EC}+10 \mathrm{RACeC}+500 \mathrm{EC}+20 \mathrm{RAC}$. Foram utilizados dois sexos, com duas repetições e seis animais por unidade experimental. Os animais consumiram uma dieta isonutritiva (Tabela 1), seguindo as exigências nutricionais do NRC (NRC, 1998), com ajustes dos níveis suplementares de aminoácidos recomendados para animais alimentados com ractopamina (APPLE et al., 2004). Os animais receberam alimentação à vontade e tiveram livre acesso à água.

Os dados de ganho de peso foram obtidos por pesagens semanais e individuais dos animais. O consumo diário de ração foi obtido pela pesagem da ração fornecida menos as sobras diárias presentes nos comedouros. A conversão alimentar foi estimada a partir das variáveis anteriores. As características de carcaça foram estimadas com ultrassom da meia carcaça esquerda, na posição P2, a $65 \mathrm{~mm}$ da linha de corte da carcaça. As medidas foram realizadas com aparelho Hennessy (HGP4 - Hennessy Grade Probe 4).

Os dados obtidos foram submetidos à análise de variância pelo procedimento GLM em nível de 5\% de significância. Os efeitos incluídos no modelo analítico foram tratamentos (T) e sexo (S). As eventuais diferenças entre as médias foram comparadas pelo teste de Tukey. As análises estatísticas foram realizadas com o programa estatístico Minitab (MCKENZIE \& GOLDMAN, 1999).

\section{RESULTADOS E DISCUSSÃO}

Os resultados de desempenho são apresentados na tabela 2 . O peso vivo, o consumo de ração, o ganho de peso e a conversão alimentar não foram afetados significativamente pela adição de ractopamina e extratos cítricos nas dietas. Estes resultados de desempenho para animais suplementados com ractopamina são condizentes com outro estudo (MIMBS et al., 2005). Porém, outro trabalho demonstrou que a ractopamina melhora o desempenho animal (CARR et al., 2005). Essas respostas divergentes são comuns na literatura e podem ser explicadas pela utilização de diferentes populações genéticas, nível de inclusão do agonista, período de fornecimento, nível de lisina e relação lisina/energia metabolizável (SMITH et al., 1995).

Animais com alto potencial genético apresentam maior taxa de deposição muscular quando suplementados com ractopamina. Esta resposta pode estar relacionada ao maior número de fibras musculares de suínos selecionados para maior deposição proteica, o que expõe um maior número de células à ação dos agonistas beta-adrenérgicos (AALHUS et al., 1992). 
Tabela 1 - Composição centesimal e calculada das dietas de suínos em crescimento e terminação.

\begin{tabular}{|c|c|c|}
\hline \multirow{2}{*}{ Ingrediente } & \multirow[b]{2}{*}{ Inicial $(60-84 \mathrm{~kg})$} & \multirow{2}{*}{ Final $(84-110 \mathrm{~kg}$ ) } \\
\hline & & \\
\hline Farelo de milho (\%) & 67,70 & 70,70 \\
\hline Farelo de soja (\%) & 28,27 & 25,42 \\
\hline Óleo de soja (\%) & 1,02 & 0,88 \\
\hline L-Lys $\mathrm{HCl}(\%)$ & 0,01 & 0,01 \\
\hline Premix vitamínico ${ }^{1}(\%)$ & 3,00 & 3,00 \\
\hline Ractopamina (ppm) ${ }^{3}$ & $0 / 10 / 20$ & $0 / 10 / 20$ \\
\hline Extratos cítricos (ppm $)^{4}$ & $0 / 250 / 500$ & $0 / 250 / 500$ \\
\hline MS (\%) & $\begin{array}{c}\text { lores nutricionais } \\
89,37\end{array}$ & 89,36 \\
\hline $\mathrm{EM}\left(\mathrm{kcal} \mathrm{kg}^{-1}\right)$ & 3.300 & 3.300 \\
\hline PB (\%) & 18,00 & 17,00 \\
\hline $\mathrm{Ca}(\%)$ & 0,67 & 0,67 \\
\hline $\mathrm{P}(\%)$ & 0,54 & 0,53 \\
\hline P disponível (\%) & 0,18 & 0,18 \\
\hline Lisina digestível (\%) & 1,02 & 0,95 \\
\hline Metionina $(\%)$ & 0,33 & 0,32 \\
\hline Triptofano digestível (\%) & 0,21 & 0,19 \\
\hline
\end{tabular}

${ }^{1}$ Suplemento mineral e vitamínico por quilograma do produto - P Max, 57g; P Mín, 54g; Na, 51g; Lis, 12g; Met, 15g; Ca, 188g, Ca Máx, 214g; K3, 80mg; Ác. Fólico, 10mg; Co, 10mg; Cu, 433mg; Cr, 6,67mg; Mn, 1000mg; Vit B12, 116,6mg; Vit B1, 26,6mg; Vit B6, 33mg; Vit E, 335mg; I, 33,4; Ác nicotínico, 600mg; Se, 8,3mg; Colistina, 4,157mg; Antioxidante, 250mg; Ác Pantotênico, 400mg; Zn, 2332mg; Fe, 2500mg; Flúor, 760mg; Vit B12, 400mcg; Vit D3, 30.000UI; Vit A, 113.000UI.

${ }^{2}$ Com base no alimento.

${ }^{3}$ Níveis de ractopamina nas dietas.

${ }^{4}$ Níveis de extratos cítricos nas dietas.

Tabela 2 - Desempenho de suínos em terminação alimentados com ractopamina e extratos cítricos.

\begin{tabular}{|c|c|c|c|c|}
\hline \multirow{2}{*}{ Tratamentos } & \multirow[b]{2}{*}{$\mathrm{PV}, \mathrm{kg}$} & \multirow[b]{2}{*}{ CMDR, $\mathrm{kg}$} & \multirow[b]{2}{*}{ GMDP, $\mathrm{kg}$} & \multirow[b]{2}{*}{$\mathrm{CA}$} \\
\hline & & & & \\
\hline Controle & 108,3 & 2,72 & 0,96 & 2,85 \\
\hline 10RAC & 109,0 & 2,65 & 1,02 & 2,58 \\
\hline 20RAC & 112,2 & 2,60 & 0,98 & 2,85 \\
\hline $250 \mathrm{EC}$ & 107,3 & 2,66 & 0,95 & 3,03 \\
\hline $500 \mathrm{EC}$ & 109,0 & 2,77 & 1,01 & 2,85 \\
\hline $10 \mathrm{RAC}+250 \mathrm{EC}$ & 111,8 & 2,73 & 1,05 & 2,64 \\
\hline $20 \mathrm{RAC}+250 \mathrm{EC}$ & 109,7 & 2,58 & 1,04 & 2,55 \\
\hline $10 \mathrm{RAC}+500 \mathrm{EC}$ & 113,6 & 2,70 & 1,05 & 2,64 \\
\hline $20 \mathrm{RAC}+500 \mathrm{EC}$ & 112,2 & 2,60 & 1,07 & 2,52 \\
\hline Médias & 110,3 & 2,66 & 1,01 & 2,72 \\
\hline CV $(\%)$ & 3,28 & 11,52 & 18,50 & 13,80 \\
\hline Desvio padrão residual & 3,23 & 0,17 & 0,08 & 0,22 \\
\hline Tratamentos & $0,12^{\mathrm{ns}}$ & $0,57^{\mathrm{ns}}$ & $0,45^{\mathrm{ns}}$ & $0,06^{\mathrm{ns}}$ \\
\hline Sexo (bloqueamento) & $0,01^{*}$ & $0,01^{*}$ & $0,01 *$ & $0,01^{*}$ \\
\hline
\end{tabular}

RAC - ractopamina; EC - extratos cítricos; PV - peso vivo; CMDR - consumo médio diário de ração; GMDP - ganho médio diário de peso; CA - conversão alimentar; CV (\%) - coeficiente de variação. ns: não significativo.

*: significativo em nível de $5 \%$ de probabilidade. 
No entanto, em nosso estudo, trabalhamos com animais meio-irmãos paternos, o que provavelmente não influenciou na resposta à ractopamina. Normalmente níveis de inclusão entre 10 ou 20ppm de ractopamina proporcionam maior ganho de peso e melhor eficiência alimentar (APPLE et al., 2004). No entanto, é provável que exista uma relação inversa entre potencial de deposição de carne magra e níveis de ractopamina (SCHINCKEL et al., 2003). Porém, neste estudo foi possível observar que níveis de inclusão entre $10 \mathrm{ou}$ $20 \mathrm{ppm}$ de ractopamina não influenciam o desempenho dos animais na terminação. Os melhores resultados para desempenho e características de carcaça em animais suplementados com ractopamina são obtidos com um aporte suplementar de 7\% de lisina na dieta (SCHINCKEL et al., 2003). As exigências de lisina e energia metabolizável para a deposição de carne magra em suínos durante a fase de terminação é de $0,69 \%$ e $3,26 \mathrm{Mcal} \mathrm{kg}^{-1}$, o que equivale à relação lisina/energia de 2,1. $\mathrm{g} \mathrm{Mcal}^{-1}$ (NRC, 1998). Em nosso trabalho, os animais receberam níveis suplementares de aminoácidos para animais alimentados com ractopamina, e o desempenho não foi afetado pelos tratamentos.

O período de utilização prolongado da ractopamina pode explicar a ausência de efeito no desempenho, pois, em nosso estudo, o período experimental foi de 52 dias. Isto pode ser explicado pelas ações da ractopamina, as quais são intracelulares sequenciais à estimulação dos receptores betaagonistas (GONZALEZ \& DA SILVA, 2006). O complexo agonista/receptor se fixa a uma proteína de ligação que modifica a fluidez da membrana, permite o seu deslocamento lateral e estimula a ação catalítica da adenilato ciclase (LEHNINGER et al., 2007). Esta participa da formação do AMPc a partir do ATP, passando a atuar como segundo mensageiro. O AMPc ativa a proteína quinase, que conduz à fosforilação de enzimas, responsáveis pela resposta final (estimulação da lipólise, aumento da neoglicogênese, glicogenólise, aumentos da insulina, do glucagon e da renina, relaxamento da musculatura lisa e aumento da contração cardíaca) (MOODY et al., 2000).

No entanto, sob ação contínua do agonista beta-adrenérgico, o AMPc ativa uma proteína quinase, que, ao fosforilar o receptor, o torna inativo e desacopla o complexo receptor-proteína de ligação-adenilato ciclase (MOODY et al., 2000). O efetor desacoplado passa para o espaço intracitoplasmático, o que diminui o número de receptores disponíveis na membrana. Essa redução no número de receptores é denominada dessensibilização e causa diminuição da resposta à estimulação beta-adrenérgica da ractopamina (MILLS, 2002). Além disso, no espaço intracitoplasmático, o receptor beta-adrenérgico pode ser consumido, fenômeno este chamado de sequestro, o que acarreta diminuição do número de receptores celulares (BENOVIC et al., 1988). Esta variação no número de receptores por unidade de sarcolema é denominada down-regulation (BARROS et al., 1999). Portanto, é possível que esses fenômenos possam ter ocorrido neste estudo.

O consumo alimentar dos animais suplementados com ractopamina foi semelhante e está de acordo com resultados obtidos em outra pesquisa realizada por AALHUS et al. (1992). Estes resultados diferem, no entanto, daquele com redução de $7 \%$ no consumo diário de ração dos animais suplementados com ractopamina (MIMBS et al., 2005). A ingestão alimentar é influenciada por vários hormônios, dentre eles a leptina. A síntese de leptina é diretamente proporcional ao acúmulo de tecido adiposo (HAVEL, 2000). As ações catabólicas do tecido adiposo são reguladas pelo sistema nervoso simpático (PÉNICAUD et al., 2000). Assim, se a inervação simpática for ativada pelos agonistas beta-adrenérgicos, há redução da expressão gênica da leptina (HAVEL, 2000). Essa inibição da expressão gênica da leptina pelo uso da ractopamina pode ter ocorrido com os animais utilizados neste trabalho, justificando, assim, a ausência de redução no consumo alimentar. Entretanto, os diversos fatores abordados anteriormente para explicar o consumo alimentar estão em desacordo com outras pesquisas, pois o uso da ractopamina na dieta reduz o consumo de alimento (APPLE et al., 2007), mas não influencia o ganho de peso (MIMBS et al., 2005). Esta redução no consumo estaria relacionada à maior densidade energética das dietas, as quais não alteram o ganho médio diário, mas deprimem o consumo de alimentos (WEBER et al., 2006). Porém, outro estudo observou que a densidade energética não altera o consumo em animais suplementados com ractopamina (APPLE et al., 2004). Apesar de haver algumas discordâncias com relação ao efeito da suplementação de ractopamina sobre o consumo alimentar, de modo geral, maiores ganhos de peso foram observados (STOLLER et al., 2003). No presente estudo, porém, o ganho de peso não foi afetado pela ractopamina.

As características de carcaça obtidas são apresentadas na tabela 3 . O comprimento de carcaça (CC), a profundidade de músculo e o $\mathrm{pH}$ não foram afetados significativamente pelos tratamentos. Os animais suplementados com $20 \mathrm{ppm}$ de ractopamina apresentaram peso de carcaça 5,7\% superior em relação ao grupo com 10ppm de ractopamina. A espessura de toucinho do grupo controle foi em média $35 \%$ superior em relação aos animais com ractopamina e com a 
Tabela 3 - Peso de carcaça (PCarc), comprimento de carcaça (CC), profundidade de músculo (PM), espessura de toicinho (ET), carne magra $(\mathrm{CM} \%)$ e (CMkg), $\mathrm{pH} 45 \mathrm{~min}$ e pH 24h de suínos em terminação alimentados com ractopamina e extratos cítricos.

\begin{tabular}{|c|c|c|c|c|c|c|c|c|}
\hline \multirow{2}{*}{ Tratamentos } & \multirow[b]{2}{*}{ PCarc, kg } & \multirow[b]{2}{*}{$\mathrm{CC}, \mathrm{cm}$} & \multirow[b]{2}{*}{$\mathrm{PM}, \mathrm{mm}$} & \multirow[b]{2}{*}{$\mathrm{ET}, \mathrm{mm}$} & \multirow[b]{2}{*}{$\mathrm{CM}, \%$} & \multirow[b]{2}{*}{$\mathrm{CM}, \mathrm{kg}$} & \multirow[b]{2}{*}{$\mathrm{pH}, 45^{\prime}$} & \multirow[b]{2}{*}{$\mathrm{pH}, 24 \mathrm{~h}$} \\
\hline & & & & & & & & \\
\hline Controle & $80,8^{\mathrm{a}}$ & 97,6 & 52,6 & $15,8^{\mathrm{a}}$ & $56,0^{\mathrm{b}}$ & $45,2^{\mathrm{a}}$ & 5,93 & 6,05 \\
\hline 10RAC & $76,4^{\mathrm{b}}$ & 96,3 & 54,2 & $11,9^{\mathrm{b}}$ & $58,9^{\mathrm{a}}$ & $44,7^{\mathrm{b}}$ & 5,88 & 6,06 \\
\hline 20RAC & $82,0^{\mathrm{a}}$ & 97,0 & 57,8 & $11,1^{\mathrm{b}}$ & $59,1^{\mathrm{a}}$ & $48,5^{\mathrm{a}}$ & 5,90 & 6,00 \\
\hline $250 \mathrm{EC}$ & $78,4^{\mathrm{a}}$ & 97,3 & 57,3 & $14,6^{\mathrm{ab}}$ & $57,6^{\mathrm{a}}$ & $45,1^{\mathrm{a}}$ & 5,82 & 6,07 \\
\hline $500 \mathrm{EC}$ & $79,6^{\mathrm{a}}$ & 99,6 & 54,9 & $14,4^{\mathrm{ab}}$ & $57,2^{\mathrm{a}}$ & $45,6^{\mathrm{a}}$ & 5,89 & 6,04 \\
\hline $10 \mathrm{RAC}+250 \mathrm{EC}$ & $80,1^{\mathrm{a}}$ & 96,5 & 56,7 & $12,5^{\mathrm{ab}}$ & $58,6^{\mathrm{a}}$ & $47,0^{\mathrm{a}}$ & 5,94 & 5,88 \\
\hline $20 \mathrm{RAC}+250 \mathrm{EC}$ & $81,2^{\mathrm{a}}$ & 95,1 & 57,0 & $12,9^{\mathrm{ab}}$ & $58,5^{\mathrm{a}}$ & $47,5^{\mathrm{a}}$ & 5,89 & 6,13 \\
\hline $10 \mathrm{RAC}+500 \mathrm{EC}$ & $80,8^{\mathrm{a}}$ & 97,7 & 56,9 & $12,0^{\mathrm{b}}$ & $58,9^{\mathrm{a}}$ & $47,7^{\mathrm{a}}$ & 5,80 & 6,04 \\
\hline $20 \mathrm{RAC}+500 \mathrm{EC}$ & $81,7^{\mathrm{a}}$ & 96,4 & 57,7 & $12,4^{\mathrm{ab}}$ & $58,9^{\mathrm{a}}$ & $48,7^{\mathrm{a}}$ & 6,02 & 6,11 \\
\hline Médias & 80,11 & 97,05 & 56,12 & 13,06 & 58,18 & 46,66 & 5,89 & 6,04 \\
\hline CV (\%) & 3,95 & 2,98 & 9,79 & 17,70 & 3,09 & 5,18 & 4,83 & 5,44 \\
\hline Desvio padrão residual & 2,21 & 2,51 & 4,7 & 2,35 & 1,35 & 1,75 & 0,17 & 0,13 \\
\hline Tratamentos & $0,01^{*}$ & $0,47^{\mathrm{ns}}$ & $0,79^{\mathrm{ns}}$ & $0,01^{*}$ & $0,01 *$ & $0,01 *$ & $0,78^{\mathrm{ns}}$ & $0,38^{\mathrm{ns}}$ \\
\hline Sexo (bloqueamento) & $0,10^{\mathrm{ns}}$ & $0,16^{\mathrm{ns}}$ & $0,10^{\mathrm{ns}}$ & $0,01 *$ & $0,01 *$ & $0,17^{\mathrm{ns}}$ & $0,51^{\mathrm{ns}}$ & $0,73^{\mathrm{ns}}$ \\
\hline
\end{tabular}

RAC - Ractopamina; EC - Extratos cítricos; ${ }^{\mathrm{a}, \mathrm{b}}$ letras diferentes na mesma coluna diferem, pelo Teste de Tukeyem, em nível de $5 \%$ de probabilidade; CV (\%) - coeficiente de variação. ns: não significativo.

*: significativo em nível de $5 \%$ de probabilidade.

interação $10 \mathrm{ppm}$ de ractopamina $+500 \mathrm{ppm}$ de extratos cítricos. A percentagem de carne magra do grupo controle foi inferior aos demais tratamentos. Em relação aos níveis de ractopamina, a percentagem de carne magra do grupo controle foi 5,1 e $5,5 \%$ inferior aos tratamentos com $10 \mathrm{ppm}$ e $20 \mathrm{ppm}$ de ractopamina, respectivamente.

As características de carcaça obtidas, em nosso trabalho, podem ser explicadas pelos efeitos da inclusão da ractopamina e de interações com extratos cítricos nas dietas. A ractopamina, além de estimular a síntese proteica, pode aumentar a apoptose no tecido adiposo, o que explicaria a menor deposição de gordura na carcaça (WEBER et al., 2006). Por outro lado, a inibição da ligação da insulina aos receptores adrenérgicos dos adipócitos antagoniza a ação da insulina, aumenta a atividade lipolítica, além de diminuir a síntese e a deposição de gordura na carcaça (MILLS, 2002). Em consequência dessas alterações metabólicas, há um aumento da síntese proteica, o que melhora a qualidade de carcaça (MOODY et al., 2000).

A ractopamina e outras fenatolaminas aumentam a percentagem de carne por serem substâncias que estimulam a deposição de nutrientes na carcaça em relação à deposição nos órgãos internos (ETHERTON \& SMITH, 1991). Assim, pode-se sugerir que, no presente estudo, a deposição muscular aumentou numa proporção maior que o crescimento dos órgãos viscerais, de maneira a aumentar o rendimento de carcaça nos suínos suplementados com ractopamina. Estas observações sugerem uma resposta positiva na carcaça pela inclusão de níveis mais altos de ractopamina.

Os tratamentos com inclusão de extratos cítricos às dietas não melhorou o desempenho $\mathrm{e}$ algumas características de carcaça. Em nosso estudo, a percentagem de carne magra foi afetada pela inclusão da ractopamina, de extratos cítricos e suas interações comparadas ao grupo controle. De acordo com a literatura, a ação dos extratos cítricos está relacionada com o sinergismo entre os bioflavonoides e o ácido ascórbico com efeitos sobre a redução do dano oxidativo (NIJVELDT et al., 2001). A ação antioxidante destes compostos aumenta a imunidade mediada ou não por células, o que diminui a susceptibilidade dos animais às doenças causadas pelo estresse (PETERSON \& DWYER, 1998). Estudos demonstram melhora no $\mathrm{pH}$, na capacidade de retenção de água e na cor do músculo (por redução da peroxidação lipídica) durante o armazenamento da carne de suínos suplementados com ácido ascorbico e bioflavonoides na dieta (JAMILAH et al., 2009).

Em nosso estudo, embora a espessura de toucinho tenha sido afetada apenas pela ractopamina 
e $10 \mathrm{ppm}$ de ractopamina $+500 \mathrm{ppm}$ de extratos, a percentagem de carne magra foi influenciada por todos os tratamentos comparados ao controle. Isto demonstra o efeito positivo da ractopamina, de extratos cítricos e suas interações sobre a percentagem de carne magra na carcaça. As demais variáveis de desempenho e carcaça possivelmente não sejam influenciadas pela inclusão de extratos cítricos às dietas.

\section{CONCLUSÃO}

A adição de ractopamina, extratos cítricos e suas interações às dietas de suínos em terminação não altera o desempenho dos animais. A inclusão de ractopamina à dieta de suínos em terminação diminui a espessura de toucinho na carcaça. Os níveis de 20ppm de ractopamina aumentam o peso e a deposição de carne magra na carcaça. A inclusão de ractopamina, extratos cítricos e suas interações nas dietas aumenta a percentagem de carne magra na carcaça.

\section{REFERÊNCIAS}

AALHUS, J.L. et al. The effect of ractopamine on myofibre distribution and morphology and their relation to meat quality in swine. Meat Science, v.31, p.397-409, 1992. Disponível em: <http://www.sciencedirect.com/science/article/B6T9G49NR301-12/2/36fdef2a66bc60b6b6d2d495ae00bfb2>. Acesso em: 11 jan. 2010. doi: 10.1016/0309-1740(92)90023-W.

APPLE, J.K. et al. Effects of dietary lysine and energy density on performance and carcass characteristics of finishing pigs fed ractopamine. Journal of Animal Science, v. 82, p.32773287, 2004. Disponível em: <http://jas.fass.org/cgi/content/ abstract/82/11/3277>. Acesso em: 20 jan. 2010.

APPLE, J.K. et al. Interactive effect of ractopamine and dietary fat source on quality characteristics of fresh pork bellies. Journal of Animal Science, v.85, p.2682-2690, 2007. Disponível em: $<\mathrm{http}: / /$ jas.fass.org/cgi/content/abstract/85/10/ 2682>. Acesso em: 21 jan. 2010. doi: 10.2527/jas.20070174 .

BARROS, R.D.A. et al. Via beta-adrenérgica em corações normais e hipertrofiados. Arquivos Brasileiros de Cardiologia, v.72, p.641-648, 1999. Disponível em: <http://publicacoes.cardiol.br/ abc/1999/7205/72050012.pdf $>$. Acesso em: 25 fev. 2010. doi: 10.1590/S0066-782X1999000500012.

BENOVIC, J.L. et al. Regulation of adenylyl cyclase-coupled betaadrenergic receptors. Annual Review of Cell Biology, v.4, p.405428, 1988. Disponível em: <http://arjournals.annualreviews.org/ doi/abs/10.1146/annurev.cb.04.110188.002201>. Acesso em: 25 fev.2010. doi:10.1146/annurev.cb.04.110188.002201.

CARR, S.N. et al. The effects of ractopamine hydrochloride on lean carcass yields and pork quality characteristics. Journal of Animal Science, v.83, p.2886-2893, 2005. Disponível em: <http://jas.fass.org/cgi/content/abstract/83/12/2886>. Acesso em: 22 mar. 2010.
CUSHNIE, T.P.; LAMB, A.J. Antimicrobial activity of flavonoids. International Journal of Antimicrobial Agents, v.26, p.343-356, 2005. Disponível em: <http:// www.ncbi.nlm.nih.gov/pubmed/16323269>. Acesso em: 22 jun. 2009. doi: 10.1016/j.ijantimicag.2005.09.002.

ETHERTON, T.D.; SMITH, S.B. Somatotropin and betaadrenergic agonists: their efficacy and mechanisms of action. Journal of Animal Science, v.69, p.2-26, 1991. Disponível em: <http://jas.fass.org>. Acesso em: 10 abr. 2009.

GONZALEZ, F.H.D.; DA SILVA, S.C. Introdução a bioquímica clínica veterinária. Porto Alegre, RS: UFRGS, 2006. 360p

HAVEL, P.J. Role of adipose tissue in body-weight regulation: mechanisms regulating leptin production and energy balance. Proceedings of the Nutrition Society, v.59, p.359-371, 2000. Disponível em: <http://journals.cambridge.org/ download.php? file $=\% 2$ FPNS\%2FPNS59_03\%2FS0029 665100000410a.pdf\&code $=0 \mathrm{e} 7 \mathrm{~b} 867 \mathrm{ba} 9480 \mathrm{~d} 3 \mathrm{e} 28 \mathrm{e} 851 \mathrm{f} 47 \mathrm{f} 408 \mathrm{cbf}>$. Acesso em: 22 jul. 2009. doi: 10.1017/S0029665100000410.

JAMILAH, B. et al. A review on the effect of animal diets and presence of selected natural antioxidants on lipid oxidation of meat. Journal of Food, Agriculture \& Environment, v.7, p.76-81, 2009. Disponível em: <http://www.isfae.org/ scientficjournal/2009/issue2/pdf/food/f11.pdf $>$. Acesso em: 12 fev. 2010.

LEHNINGER, A.L. et al. Princípios de bioquímica. 4.ed. São Paulo: Sarvier, 2007. 1232p.

MASON, L.M. et al. Effects of restricted feeding and antioxidant supplementation on pig performance and quality characteristics of Longissimus dorsi muscle from Landrace and Duroc pigs. Meat Science, v.70, p.307-317, 2005. Disponível em: <http:/ /www.sciencedirect.com/science/article/B6T9G-4FPDRGF-1/2/ 1183beb1235ab8fb48a3c757bbabc234>. Acesso em: $22 \mathrm{dez}$. 2009. doi: 10.1016/j.meatsci.2005.01.017.

MCKENZIE, J.; GOLDMAN, R.N. The student edition of minitab for windows manual. Softcover ed. Belmont: Addison-Wesley Longman, 1999. 592p.

MILLS, S.E. Implications of feedback regulation of betaadrenergic signaling. Journal of Animal Science, v.80 (E. Suppl. 1), p.30-35, 2002. Disponível em: <http://www.asas.org/ symposia/vol80/jas1710.pdf>. Acesso em: 16 mar. 2010.

MIMBS, K.J. et al. Effects of ractopamine on performance and composition of pigs phenotypically sorted into fat and lean groups. Journal of Animal Science, v.83, p.13611369, 2005. Disponível em: <http://jas.fass.org/cgi/content/ abstract/83/6/1361>. Acesso em: 15 dez. 2009.

MOODY, D.E. et al. Phenethanolamine repartitioning agents. In: MELLO, J.P.F.D. Farm animal metabolism and nutrition. New York: CAB, 2000. p.65-95.

NIJVELDT, R. J. et al. Flavonoids: a review of probable mechanisms of action and potential applications. Americam of Journal and Clinical Nutritional, v.74, p.418-425, 2001. Disponível em: <http://www.ajcn.org/cgi/reprint/74/4/418.pdf> Acesso em: 10 ago. 2009. 
NRC. Nutrient requirements of swine. 10.ed. Washington: National Academy, 1998. 189p.

PADAYATTY, S.J. et al. Vitamin C as an antioxidant: evaluation of its role in disease prevention. Journal of the American College of Nutrition, v.22, p.18-35, 2003. Disponível em: $<$ http://www.jacn.org/cgi/reprint/22/1/18.pdf $>$. Acesso em: 19 jan. 2010.

PÉNICAUD, L. et al. The autonomic nervous system, adipose tissue plasticity, and energy balance. Nutrition, v.16, p.903908, 2000. Disponível em: <http://www.sciencedirect.com/ $\mathrm{sc}$ i e n c e/article/B 6 T B $0-41 \mathrm{H} 3 \mathrm{~K} \mathrm{~T} \mathrm{D} \mathrm{-} \mathrm{F/} \mathrm{2/}$ 2712fdd0da3bc3bac7e382ae362e58a7>. Acesso em: $13 \mathrm{dez}$. 2009. doi: 10.1016/S0899-9007(00)00427-5.

PETERSON, J.; DWYER, J. Flavonoids: dietary occurrence and biochemical activity. Nutrition Research, v.18, p.1995-2018, 1998. Disponível em: <http://www.sciencedirect.com/ science?_ob=ArticleURL\&_udi=B6TB1-3W28S1K$7 \&$ user $=10 \&$ rdoc $=1 \&$ fmt $=\&$ orig $=$ search \& sort $=d$ $\& \_$docanchor $=\&$ view $=$ c \&_searchStrId $=955225490 \&$ rerunOrigin $=$ google\&_acct $=\mathrm{C} 000050221 \&$ _version $=1 \&$ \&urlVersi $\overline{\text { on }}=0 \&$ \&userid $=10 \& \mathrm{md} 5=\mathrm{b} 93766 \mathrm{~b} 5509 \mathrm{~b} 169 \overline{\mathrm{dcfa}} 780 \mathrm{f} 07536 \mathrm{c} 4 \mathrm{ea}>$. Acesso em: 05 dez. 2009. doi: 10.1016/S0271-5317(98)00169-9.

PION, S.J. et al. Effects of vitamin C supplementation on plasma ascorbic acid and oxalate concentrations and meat quality in swine. Journal of Animal Science, v.82, p.2004-2012,
2004. Disponível em: <http://jas.fass.org/cgi/content/abstract/ 82/7/2004>. Acesso em: 14 set. 2009.

SCHINCKEL, A.P. et al. Ractopamine treatment biases in the prediction of pork carcass composition. Journal of Animal Science, v.81, p.16-28, 2003. Disponível em: <http:// jas.fass.org/cgi/content/abstract/81/1/16>. Acesso em: 10 nov. 2009.

SMITH, W.C. et al. Effects of ractopamine on the growth and carcass quality of entire male and female pigs fed ad libitum or at a restricted level. New Zealand Journal of Agricultural Research, v.38, p.373-380, 1995. Disponível em: <http:// www.royalsociety.org.nz/Site/publish/Journals/nzjar/1995/ 105. aspx>. Acesso em: 18 jan. 2010. doi: 0028-8233/95/ 3803-0373.

STOLLER, G.M. et al. The effect of feeding ractopamine (Paylean) on muscle quality and sensory characteristics in three diverse genetic lines of swine. Journal of Animal Science, v.81, p.1508-1516, 2003. Disponível em: <http://jas.fass.org/ cgi/content/abstract/81/6/1508>. Acesso em: 13 fev. 2010.

WEBER, T.E. et al. Evaluation of the effects of dietary fat, conjugated linoleic acid, and ractopamine on growth performance, pork quality, and fatty acid profiles in genetically lean gilts. Journal of Animal Science, v.84, p.720-732, 2006. Disponível em: <http://jas.fass.org/cgi/content/abstract/ 84/3/720>. Acesso em: 15 out. 2009. 